\title{
A compreensão intuitiva da criança acerca da divisão partitiva de quantidades contínuas
}

Jane Correa

Universidade Federal do Rio de Janeiro

Elisabet de Sousa Meireles

Cristina Soraia de Souza Curvelo

Resumo

Investiga-se o entendimento intuitivo que crianças entre 5 a 7 anos de idade têm da divisão partitiva envolvendo quantidades contínuas em tarefas em que tenham que estimar o valor relativo dos quocientes em vez de calcular o seu valor absoluto. Foi observado progressivo desenvolvimento com a idade das habilidades das crianças em lidar com a relação de ordem inversa entre divisor e quociente. Importantes mudanças acontecem, também, em relação aos tipos de justificativas de resolução da tarefa. Há um aumento com a idade da porcentagem de justificativas que fazem menção a fatores que são matematicamente relevantes à solução do problema, decrescendo a frequiência de respostas sem justificativas ou acompanhadas por justificativa arbitrária. Os resultados indicam que a experiência em estabelecer comparações entre partilhas idênticas precede e parece constituir experiência fundamental à criança para a compreensão das relações entre os termos envolvidos na operação de divisão, principalmente no julgamento das relações de covariação inversa.

Palavras-chave: divisão partitiva, quantidades contínuas, aritmética. 
Key words: partitive division, continuous quantities, arithmetic.

\section{Abstract}

Children's intuitive understanding of partitive division tasks using continuous quantities

This study investigated 5- to 7-year-old children's understanding of partitive division tasks using continuous quantities. The children were asked to estimate the relative value of the quotients instead of their absolute values. A progressive increase in children's abilities to deal with the inverse divisor-quotient relationship was observed. Important changes occurred in relation to the type of justification given. There was an increase with age in the percentage of responses accompanied by justifications which focused on the mathematical information relevant to the solution of the task. The results also suggested that the experience of comparing identical share-outs precede and may lead the growth of the children's understanding of the relationships between division terms.

divisão é uma operação matemática comumente associada a
problemas envolvendo repartir uma determinada quantidade
em um certo número de quotas, como, por exemplo, na situação em que pretendemos dividir um tanto de balas por um determinado número de crianças. Este aspecto da operação de divisão é denominado partitivo, pois envolve a separação exaustiva de uma classe em subclasses disjuntas.

Fischbein, Deri, Nello e Marino (1985) sugerem que cada uma das quatro operações aritméticas fundamentais estaria associada a determinados modelos intuitivos. Tais modelos influenciariam o desempenho dos indivíduos ao solucionar um problema, mediando, entre outros aspectos, o processo de identificação da operação necessária à resolução da tarefa. Em função das evidências empíricas em favor da maior facilidade com que os problemas de divisão partitiva são resolvidos pelos sujeitos quando comparados a outros tipos de problemas 
de divisão, os autores consideram o aspecto partitivo da divisão como sendo o modelo intuitivo da operação aritmética de divisão.

Brown (1981), investigando a dificuldade relativa aos modelos associados às quatro operações aritméticas básicas, pediu a estudantes ingleses de 11 a 13 anos de idade, classificados em diferentes níveis de habilidade para matemática, que formulassem problemas associados a cada uma destas operações. Para o sinal de divisão, quase a totalidade dos estudantes formulou problemas de divisão partitiva.

Embora não sendo este o único modelo possível de ser associado à operação de divisão (ver a este respeito, Greer, 1992), o aspecto partitivo da divisão aparece com maior freqüência na vida diária das crianças, envolvendo principalmente a distribuição de determinada quantidade entre certo número de pessoas.

De fato, as situações quotidianas de repartir com as quais as crianças mais novas se defrontam podem ser modeladas, do ponto de vista matemático, pelo algoritmo da divisão. Em relação aos esquemas de ação envolvidos, estas mesmas situações podem ser relacionadas à operação de divisão a partir do uso da correspondência termo a termo e da noção de equivalência.

No entanto, conforme discutido por Correa (1995) e Correa, Nunes e Bryant (1998), o aspecto partitivo da operação de divisão e as experiências quotidianas de repartir não podem ser tomadas como sinônimos. Ao repartir, a criança se vale principalmente dos esquemas de correspondência com o objetivo de estabelecer a equivalência entre as partes. Para tal, a criança pode lançar mão apenas de procedimentos de caráter aditivo onde tudo o que necessita fazer, por exemplo, é repetir o mesmo conjunto de ações até que não haja mais elementos disponíveis para uma segunda distribuição. Neste processo, a equivalência é conseguida através da adição ou subtração por tateios de alguns elementos a serem distribuídos.

A operação de divisão, por outro lado, envolve conhecimento além daquele relativo à obtenção de subconjuntos equivalentes quando se reparte. Como uma operação multiplicativa, requer a coordenação dos fatores envolvidos - dividendo, divisor e quociente - através 
do entendimento das relações que estes termos podem estabelecer entre si. Por exemplo, quando mantemos o divisor constante, o quociente varia diretamente em função do tamanho do dividendo: quanto maior o dividendo, maior será o tamanho do quociente (isto é, o tamanho da quota).

Investigações acerca da relação entre a experiência quotidiana da criança ao partilhar e o seu conhecimento intuitivo de divisão (Correa, 1995; Correa \& Bryant, 1994; Correa et al., 1998) indicam que esta experiência, embora necessária, não é suficiente para que a criança entenda as relações estabelecidas entre os termos envolvidos em situações de divisão.

A maioria das crianças de 5 anos, idade em que na literatura são reputadas como tendo considerável entendimento da experiência inicial de partilhar (Desforges \& Desforges, 1980; Frydman \& Bryant, 1988; Miller, 1984), não foi capaz de estimar com sucesso o valor relativo dos quocientes nas tarefas de divisão apresentadas por Correa (1995) e Correa et al. (1998).

No entanto, nos estudos reportados acima, foi observada diferença significativa nas respostas dadas pelas crianças de 6 e 7 anos. Ao contrário das crianças de 5 anos, cerca de $55 \%$ das crianças de 6 anos e $85 \%$ das crianças de 7 anos mostraram entendimento razoável das relações estabelecidas entre os termos da operação de divisão nestas tarefas, tanto no julgamento do valor relativo dos quocientes como, também, nas justificativas dadas.

Tais resultados mostram que as crianças, ao contrário do que se poderia esperar numa perspectiva linear do ensino da aritmética, podem desenvolver um conhecimento informal acerca da operação de divisão a partir do uso de estimativas. Este conhecimento pode ser de grande valia para que a criança possa, inclusive, julgar a plausibilidade do cálculo realizado na resolução do algoritmo da divisão quando de seu ensino formal pela escola anos mais tarde.

No entanto, nem as situações-problema de divisão, nem as experiências iniciais de repartir que as crianças realizam informalmente limitam-se à distribuição de um certo número discreto de itens. Vê-se que o uso de quantidades contínuas também é bastante comum nestas 
situações, tornando-se, portanto, relevante indagarmos acerca da experiência inicial da criança em tarefas de divisão partitiva com quantidades contínuas.

O presente estudo pretendeu realizar tal investigação, escolhendo como paradigma de pesquisa aquele reportado por Correa et al. (1998). A opção metodológica por tarefas em que o cômputo aritmético não fosse requisito necessário à sua resolução baseou-se na perspectiva teórica exposta por Bryant (1974) acerca da importância dos códigos relativos para o raciocínio da criança. Estudos posteriores acerca do desenvolvimento de conceitos lógico-matemáticos (Correa, Spinillo, Brito \& Moro, 1998; Singer, Kohn \& Resnick, 1997; Spinillo \& Bryant, 1991; Streefland,1982) fornecem evidências empíricas que destacam, também, o papel desempenhado pelo uso de estimativas na construção inicial das noções de probabilidade e proporção aplicadas a quantidades contínuas.

Uma vez que seria mais fácil para a criança mais nova raciocinar com base em estimativas, a investigação acerca do conhecimento inicial da divisão de quantidades contínuas privilegiaria o julgamento do valor relativo dos quocientes e não o cálculo de seu valor absoluto. Indagaríamos, portanto, às crianças sobre as relações elementares entre as quantidades no processo de divisão não em termos absolutos (através de tarefas de cálculo), mas em termos relativos (usando relações como mais/menos que) .

Duas possibilidades podem, então, surgir, quando da investigação do entendimento intuitivo das crianças mais novas acerca das relações entre dividendo e divisor na determinação do valor do quociente através do uso de tarefas relacionais. A primeira em que se mantém o divisor constante e varia-se o dividendo. A segunda, em que se mantém constante o dividendo e modifica-se o valor dos divisores.

$\mathrm{O}$ primeiro tipo de situação não constitui uma boa tarefa se o objetivo é contrastar a experiência quotidiana de repartir e o conhecimento inicial de divisão, uma vez que o julgamento da relação direta entre dividendo e quociente pode ser feita em base aditiva tal qual na experiência inicial de partilha. A criança não precisa, portanto, coordenar mais que uma variável para ter sucesso na tarefa. 
A segunda situação, em que a criança deve julgar a relação entre divisor e quociente parece mais apropriada a este propósito pois a correta solução da tarefa implica a coordenação de duas informações: o fato de que o dividendo é mantido constante e de que o divisor varia em número. Neste sentido, o sucesso na tarefa demonstra o entendimento de uma verdadeira relação multiplicativa.

O presente estudo investigou, portanto, a compreensão que crianças de diferente idades ( 5 a 7 anos) teriam acerca das relações entre dividendo, divisor e quociente em tarefas de divisão partitiva envolvendo quantidades contínuas. As tarefas utilizadas na investigação foram do tipo relacional em que as crianças tiveram que julgar o valor relativo dos quocientes e não calcular o seu valor absoluto. Como o dividendo foi mantido constante e, foram usadas, para os divisores, quantidades maiores que a unidade, as crianças tiveram, portanto, que estimar a relação inversa entre o número de divisores e o tamanho do quociente.

\section{Método}

\section{Participantes}

Participaram deste estudo 61 crianças: 20 de 5 anos (14 meninos e 6 meninas; média de idade:5,2; amplitude: 5,0 a 5,11); 22 de 6 anos (9 meninos e 13 meninas; média de idade: 6,5; amplitude: 6,0 a 6,11); 19 de 7 anos ( 9 meninos e 10 meninas; média de idade: 7,3; amplitude: 7,0 a $7,7)$. Todas as crianças estudavam numa escola pública da cidade do Rio de Janeiro.

\section{Tarefas}

O principal objetivo das tarefas foi o de estabelecer se as crianças seriam capazes de entender a relação inversa entre divisor e quociente em uma tarefa de divisão partitiva envolvendo quantidades contínuas em que o cálculo aritmético não fosse necessário à sua solução. A tarefa consistiu em apresentar à criança dois grupos de bonecos dispostos em diferentes lados da mesa. A cada grupo de bonecos foi designada a mesma quantidade de chocolate e suco. As crianças fari- 
am, então, o julgamento sobre o tamanho relativo dos quocientes em duas condições, que foram designadas como Condição "Mesma" e Condição "Diferente".

Na condição designada como Mesma, cada grupo de bonecos tinha o mesmo número de elementos, por exemplo, 2 meninos e 2 meninas (item 2[2]). Na condição designada como Diferente, cada grupo de bonecos tinha um número diferente de elementos, por exemplo, 2 meninas e 3 meninos (item 2[3]) . O número de elementos em cada grupo variou de 2 a 4 .

Cada condição envolveu três itens. Na Condição Mesma, os itens foram: 2(2), 3(3) e 4(4). Os itens na Condição Diferente foram: 2(3), 2(4) e 3(4).

Em relação à natureza das quantidades apresentadas, um ponto interessante a considerar seria o das diferentes dimensões envolvidas no tipo de quantidade contínua a ser dividida em termos de sua possível representação (Miller, 1984). Por exemplo, a divisão de uma barra de chocolate em pedaços iguais envolveria, principalmente, um processo de partição em termos da representação bidimensional de sua superfície, ao passo que dividir o suco de laranja em copos de mesmo tamanho envolveria preferencialmente representação tridimensional. Neste sentido, seria importante investigar se diferentes tipos de quantidades contínuas levariam a diferentes padrões de entendimento. Assim sendo, dois tipos de quantidades contínuas foram usadas no presente projeto: barras de chocolate ou garrafas de suco.

Estas quantidades foram apresentadas em dois contextos aqui designados como "Numérico" e de "Tamanho". No contexto designado como Numérico, foi dito às crianças que seriam dados aos bonecos pedaços de chocolates (ou copos de suco) conforme as dimensões desenhadas num cartão. Tais dimensões corresponderiam a aproximadamente 1/12 da quantidade a ser dividida. As crianças avaliaram, então, se cada um dos bonecos em um grupo receberia maior, menor ou igual número de pedaços (ou copos de suco) que os bonecos de outro grupo. No caso do Contexto Tamanho, as crianças tiveram que avaliar o tamanho do pedaço da barra de chocolate (ou da quantidade da garrafa de suco) dado a cada boneco nos dois diferentes grupos. 


\section{Material}

O material consistiu de duas barras de chocolate e duas garrafas de água colorida de amarelo representando o suco de laranja, além de oito bonecos (4 meninas e 4 meninos). Foram apresentados, também, cartões contendo respectivamente os desenhos de um pedaço de chocolate e um copinho de suco correspondendo a 1/12 da quantidade de suco ou chocolate a ser dividida.

\section{Procedimentos}

As crianças foram entrevistadas individualmente em quatro sessões. À metade do número de crianças foram apresentadas, nas primeira e segunda sessões, tarefas nas quais o dividendo consistiu de uma barra de chocolate e, nas terceira e quarta sessões, tarefas em que o dividendo foi representado por uma garrafa de suco de laranja. À outra metade foram apresentadas, nas primeira e segunda sessões, tarefas em que o dividendo era uma garrafa de suco de laranja e nas terceira e quarta sessões, uma barra de chocolate. Tanto nas sessões em que uma barra de chocolate foi dividida, assim como nas sessões em que uma garrafa de suco foi apresentada como dividendo, metade do número de crianças iniciou as tarefas com o Contexto Numérico e a outra metade com o Contexto de Tamanho.

Os bonecos representando os meninos e as meninas foram colocados em diferentes lados da mesa. As crianças foram solicitadas a contar quantas meninas ( 2,3 ou 4 ) e quantos meninos (2, 3 ou 4) foram colocados em cada lado da mesa. Na Condição designada como Mesma, o pesquisador colocou o mesmo número de bonecos em cada grupo. Nos itens referentes à Condição Diferente, um número diferente de bonecos foi colocado em cada grupo. A posição esquerda-direita de ambos os grupos de bonecos colocados sobre a mesa variou sistematicamente, bem como, na Condição Diferente, as diferentes combinações entre meninos e meninas ( 2 meninas e 3 meninos e vice-versa).

No Contexto Tamanho, a pesquisadora disse às crianças que haveria uma barra de chocolate (ou uma garrafa de suco) a ser dividida entre o grupo de meninos e outra barra de chocolate (ou uma garrafa de suco) a ser dividida entre as meninas. A pesquisadora, então, apontou para uma menina e um menino e perguntou se eles receberiam 
pedaços de chocolate do mesmo tamanho (ou a mesma quantidade de suco) ou se um deles receberia um pedaço de chocolate maior (ou mais quantidade de suco) do que o outro.

No Contexto Numérico, a pesquisadora apresentou um cartão à criança com o desenho de um pedaço de chocolate que corresponderia a 1/12 do tamanho da barra de chocolate (ou um copo de suco correspondente a 1/12 da quantidade de suco apresentada). Ela explicou que a barra de chocolate de cada grupo seria cortada em pedaços daquele tamanho (ou que o suco seria colocado em copos do tamanho mostrado no desenho). A pesquisadora, então, apontou para uma menina e um menino e perguntou à criança se ambos receberiam o mesmo número de pedaços de chocolate (ou copos de suco) ou se um deles receberia mais pedaços de chocolate (ou copos de suco) do que o outro.

As crianças foram solicitadas a dar justificativa para cada resposta, tendo sido ela correta ou não.

\section{Resultados}

As respostas dadas pelas crianças foram analisadas de três modos: a) pela análise quantitativa das respostas corretas; b) pela análise dos erros das crianças e c) pela análise das justificativas dadas pelas crianças para cada resposta, seja esta correta ou não.

\section{Análise quantitativa das respostas corretas}

O entendimento das crianças acerca de divisão partitiva envolvendo quantidades contínuas em situações em que o valor relativo dos quocientes tem que ser estimado deve ser expresso não apenas pelos acertos em tarefas em que o número de divisores é o mesmo para ambos os grupos a serem comparados (Condição Mesma), mas, também, nas tarefas em que o número de divisores é diferente em ambos os grupos (Condição Diferente).

Nas tarefas da Condição Diferente, as crianças têm que estimar uma relação de ordem inversa entre o número de divisores e o tamanho relativo dos quocientes. Este tipo de relação não é trivial nesta faixa etária, quer porque dificilmente seja encontrada no quotidiano das crianças, quer porque implique no uso de um julgamento eminen- 
temente multiplicativo. Se a criança é capaz de resolver satisfatoriamente as tarefas em uma determinada condição, mas não em outra, não se pode dizer que ela seja, então, capaz de estimar as relações entre as quantidades envolvidas na operação de divisão partitiva com quantidades contínuas como apresentadas por nossas tarefas.

A Tabela 1 apresenta a proporção de respostas corretas em cada Condição para as diferentes tarefas apresentadas nas diversas faixas etárias. A primeira inspeção dos dados revela que o índice de acertos aumenta progressivamente com a idade. $\mathrm{O}$ desempenho das crianças parece não ser afetado pelo tipo de conteúdo a ser dividido, mas sim pelo fato das tarefas envolverem o mesmo número de bonecos em ambos os grupos ou diferente quantidade de bonecos em cada grupo. As tarefas da Condição Mesma são tidas pelas crianças como mais fáceis que as da Condição Diferente.

Tabela 1.

Proporção média de acertos por Condição, Contexto e Conteúdo em cada Idade

\begin{tabular}{|c|c|c|c|c|c|}
\hline \multirow{2}{*}{ Condição } & \multirow[b]{2}{*}{ Contexto } & \multicolumn{3}{|c|}{ Idade } & \multirow[b]{2}{*}{7} \\
\hline & & Conteúdo & 5 & 6 & \\
\hline \multirow[t]{4}{*}{ Mesma } & Tamanho & Suco & .50 & .71 & .88 \\
\hline & & Chocolate & .50 & .71 & .95 \\
\hline & Numérico & Suco & .42 & .71 & .88 \\
\hline & & Chocolate & .52 & .74 & .93 \\
\hline \multirow[t]{4}{*}{ Diferente } & Tamanho & Suco & .27 & .30 & .44 \\
\hline & & Chocolate & .20 & .27 & .35 \\
\hline & Numérico & Suco & .30 & .26 & .37 \\
\hline & & Chocolate & .30 & .30 & .37 \\
\hline
\end{tabular}

Antes de se iniciar qualquer outro tipo de análise, foi realizado o cálculo da probabilidade que cada criança teria em dar respostas corretas por mero acaso, uma vez que as respostas das crianças eram limitadas às alternativas apresentadas pelos pesquisadores.

Em cada tarefa, a criança era apresentada às seguintes alternativas: (a) os meninos e as meninas vão ganhar o mesmo tanto de chocolate ou suco cada um; (b) os meninos vão ganhar mais chocolate ou suco cada um e (c) as meninas vão ganhar mais chocolate ou suco 
cada uma. Nestas circunstâncias, há, portanto, 1/3 de chance da criança dar a resposta certa simplesmente por acaso. Como temos 12 tarefas em cada condição e 3 alternativas de resposta em cada uma das tarefas, é preciso, de acordo com a Distribuição Binomial, que a criança atinja um escore igual ou superior a $7(\mathrm{p}=.045)$ para ser considerada como tendo desempenho significativamente acima do que seria esperado por mero acaso.

A Tabela 2 mostra o número de crianças cujo desempenho teria sido considerado acima do nível de chance nas Condições Mesma e Diferente. Pode-se ver que independente da idade, mais crianças tiveram desempenho acima do esperado por mero acaso na Condição Mesma do que na Condição Diferente. A análise dos protocolos revela que destas crianças, 1 criança de 5 anos, 3 de 6 anos e 7 crianças de 7 anos mostraram desempenho superior ao esperado por mero acaso simultaneamente em ambas as condições. De acordo com estes dados, pode-se dizer que 5\% das crianças de 5 anos, $14 \%$ das de 6 anos e $37 \%$ das crianças de 7 anos revelaram desempenho acima do que seria esperado ao acaso ao estimar as relações entre as quantidades envolvidas na operação de divisão partitiva com quantidades contínuas como apresentadas pelas nossas tarefas.

Tabela 2 .

Número de crianças cujo desempenho foi considerado acima do nível de chance em cada Condição.

\begin{tabular}{ccc}
\hline & \multicolumn{2}{c}{ Condições } \\
\hline Idade & Mesma & Diferente \\
\hline 5 & 9 & 2 \\
6 & 13 & 5 \\
7 & 16 & 7 \\
\hline
\end{tabular}

Como as respostas das crianças em cada tarefa eram registradas em termos binários, isto é, como acerto/erro, os dados foram, portanto, submetidos a uma Análise de Regressão Logística para examinar a importância dos seguintes fatores, e suas respectivas interações, para a compreensão do desempenho das crianças nas tarefas: idade, condição, contexto, conteúdo e tarefa. 
Os resultados de tal análise mostram que os escores obtidos pelas crianças estão significativamente relacionados apenas à Idade $\left(\mathrm{c}^{2}\right.$ =67.58; $\mathrm{gl}=2, \mathrm{p}<.001)$ e à Condição $\left(\mathrm{c}^{2}=239.61 ; \mathrm{gl}=1, \mathrm{p}<.001\right)$. Somente a interação Idade X Condição $\left(c^{2}=34.59 ; \mathrm{gl}=2, \mathrm{p}<.001\right)$ foi significativa.

Observa-se aumento na proporção média de acertos com a idade. As crianças de 6 anos mostram melhor desempenho que as crianças de 5 anos e, por sua vez, as crianças de 7 anos têm maior índice de acertos que as crianças de 6 anos. De maneira geral, as tarefas da Condição Mesma são resolvidas mais facilmente do que as tarefas da Condição Diferente. No entanto, a análise da interação entre Idade e Condição mostra que, entre 5 e 7 anos há um aumento progressivo na proporção média de acertos para a Condição Mesma e que tal progressão não se deu da mesma maneira na Condição Diferente. Nesta última, não há diferença apreciável entre os índices de acertos das crianças de 5 e 6 anos.

\section{Análise dos Erros}

Como as respostas das crianças em cada Condição eram limitadas às alternativas apresentadas pelos pesquisadores, dois tipos de erro seriam então registrados para a Condição Diferente. As crianças poderiam dizer que tanto os meninos como as meninas ganhariam cada um o mesmo tanto de chocolate ou suco, Tipo de Erro I. As crianças ainda poderiam responder que ou o menino ou a menina que estivesse no grupo com maior número de bonecos receberia mais chocolate ou suco do que o outro que estivesse em um grupo com menor número de bonecos, Tipo de Erro II.

A tendência sistemática em apresentar o Tipo de Erro I poderia indicar que a criança estaria focalizando sua atenção somente no tamanho do dividendo, o que nas tarefas era mantido constante. Por outro lado, a preponderância de Tipo de Erro II indicaria que as crianças estariam focalizando sua atenção somente no número de divisores, ou seja, no número de bonecos em cada grupo. Uma vez que as crianças estariam negligenciando o fato de que o dividendo foi mantido constante, elas estabeleceriam uma relação do tipo direta entre divisor e quociente, em que o grupo no qual haveria mais crianças deveria, então, receber mais chocolate ou suco. 
A análise dos erros foi feita somente para a Condição Diferente uma vez que esta análise para a Condição Mesma não nos traria maiores informações sobre a compreensão que a criança tem das relações entre as quantidades na operação de divisão. Tal análise apenas revelaria preferência de gênero nas escolhas feitas por algumas crianças.

A Tabela 3 apresenta a porcentagem de respostas em cada tipo de erro de acordo com a idade. Observa-se que aos 5 anos, a freqüência relativa dos erros de Tipo I e II se distribuem quase que equiitativamente. A partir de 6 anos, há um predomínio do erro do Tipo II, ou seja, a criança afirma que quanto maior o divisor, maior também será o quociente.

Tabela 3.

Frequência relativa dos erros segundo a idade (em \%).

\begin{tabular}{ccc}
\hline & \multicolumn{2}{c}{ Tipo de Erro } \\
\hline Idade & I & II \\
\hline 5 & 45,45 & 54,55 \\
6 & 20,63 & 79,37 \\
7 & 4,96 & 95,04 \\
\hline
\end{tabular}

\section{As Justificativas}

Foi pedido às crianças que justificassem sua resposta independentemente destas serem ou não corretas. As Justificativas foram classificadas em seis categorias derivadas da classificação anteriormente apresentada por Correa (1995) e Correa et al. (1998).

\section{Justificativa I}

A criança não apresenta nenhuma justificativa ou diz não saber o porquê da resposta ou, ainda, limita-se a repetir a escolha anteriormente feita. Exemplo: "Mais para os meninos. Porque os meninos vão ganhar mais."

\section{Justificativa II}

A criança apresenta uma justificativa idiossincrática ("Porque eu gosto mais dos meninos.”), ou uma justificativa baseada na experiên- 
cia socialmente desejável em relação à partilha justa de quantidades (“Vão ganhar a mesma coisa. Porque é certo e eles não vão brigar.”).

\section{Justificativa III}

Neste tipo de justificativa, as crianças fazem menção à quantidade total a ser dividida, isto é, ao dividendo. Exemplo: "Vão ganhar igual. Porque a barra de chocolate é igualzinha."

\section{Justificativa IV}

Este tipo de justificativa só é válido nas tarefas da Condição Mesma. A criança estabelece julgamento relativo à igualdade dos valores a serem recebidos pelos bonecos em ambos os grupos. Exemplo: "Vai ser do mesmo tamanho porque tem a mesma quantidade de crianças."

\section{Justificativa $V$}

Este tipo de Justificativa só aparece na Condição Diferente. As crianças estabelecem erroneamente uma relação direta entre o número de divisores e o valor do quociente. Exemplo: "Ela vai receber mais porque têm mais menina do que menino."

\section{Justificativa VI}

A exemplo da categoria anterior, este tipo de Justificativa só aparece na Condição Diferente. Desta vez, no entanto, as crianças estabelecem apropriadamente uma relação de tipo inversa entre divisores e quocientes. Exemplo: "Eles ganham mais porque têm 2 meninos e 3 meninas, então vai sobrar mais chocolate para os meninos."

Os dois primeiros tipos de justificativa não envolveriam nenhuma menção a qualquer fato matematicamente relevante à solução da tarefa. Em duas outras categorias, Justificativas III e V, apesar das crianças focalizarem sua atenção nos fatores em jogo na situação-problema, elas o fazem de maneira inapropriada. Finalmente as duas outra categorias, Justificativas IV e VI, refletiriam apropriadamente as relações a serem estabelecidas entre os termos da divisão nas Condições Mesma e Diferente. 
A categorização das justificativas dadas pelas crianças foram feitas por dois juízes independentes. O percentual de concordância entre estes juízes foi de $92,50 \%$. A Tabela 4 apresenta a distribuição da freqüência das justificativas dadas pelas crianças de acordo com a idade nas Condições Mesma e Diferente.

Tabela 4

Distribuição das justificativas por idade nas Condições Mesma e Diferente (em \%).

\begin{tabular}{rlrrrrrr}
\hline & & \multicolumn{7}{c}{ Justificativas } \\
\hline \multirow{2}{*}{ Idade } & Condição & I & II & III & IV* & V** & VI** \\
\hline \multirow{2}{*}{5} & Mesma & 16.67 & 62.08 & 10.83 & 10.42 & .00 & .00 \\
& Diferente & 15.00 & 63.33 & 9.58 & .00 & 12.09 & .00 \\
6 & Mesma & 1.89 & 34.09 & 3.79 & 60.23 & .00 & .00 \\
& Diferente & 3.41 & 32.95 & 6.06 & .00 & 43.94 & 13.64 \\
7 & Mesma & 1.32 & 13.60 & .00 & 85.08 & .00 & .00 \\
& Diferente & .44 & 8.77 & .00 & .00 & 55.26 & 35.53 \\
\hline
\end{tabular}

* A Justificativa IV é somente apropriada para a Condição Mesma.

** As Justificativas V e VI só são possíveis na Condição Diferente.

Observa-se considerável diferença quanto ao tipo de justificativa dada pelas crianças, de acordo com a idade, em ambas as Condições. $\mathrm{Na}$ Condição Mesma, há uma progressiva transição entre 5 e 7 anos no que diz respeito a como as crianças justificam suas respostas. Em relação às crianças de 5 anos, $78.75 \%$ de suas justificativas pertencem a dois tipos de categorias: Não-Justificativa e Justificativas Idiossincráticas. Aos 6 anos, a percentagem de justificativas nestas categorias cai para $35.98 \%$, para aos 7 anos responder por pouco menos de $15 \%$ das respostas das crianças. Aos 6 e 7 anos de idade, aumenta a freqüência de Justificativas IV, que expressa apropriadamente a relação a ser estabelecida entre divisor e quociente nas tarefas da Condição Mesma.

Para a Condição Diferente, esta transição também se expressa pelo aumento da frequiência de justificativas que envolvem menção 
aos termos da operação de divisão. No entanto, nem sempre as crianças conseguem estabelecer a relação apropriada entre estes elementos, o que redunda num aumento considerável do número de Justificativas V. Novamente, a maioria das respostas das crianças de 5 anos $(78.33 \%)$ são classificadas como Justificativas I e II, não expressando nenhuma relação relevante do ponto de vista matemático para a resolução da tarefa.

A distribuição das justificativas segundo os tipos de erro encontrados na Condição Diferente (Tabela 5) varia em função da idade. Aos 5 anos, para os dois tipos de erro, a maioria das respostas é acompanhada da Justificativa II. A partir dos 6 anos, no entanto, diferenciam-se os tipos de Justificativa segundo o tipo de erro cometido. No erro de Tipo I, aumenta a freqüência das respostas acompanhadas pela Justificativa III, ressaltando, portanto, a igualdade dos dividendos em ambos os grupos. No erro de Tipo II, 77 \% das respostas são acompanhadas pela Justificativa $\mathrm{V}$, que apesar de tentar relacionar o número de divisores ao tamanho do quociente, o faz de maneira inapropriada. Aos 7 anos, as poucas respostas de erro de Tipo I são acompanhadas da Justificativa II, enquanto à quase totalidade das respostas de erro de Tipo II segue-se a Justificativa V.

Tais resultados indicam que a maior parte dos erros das crianças a partir dos 6 anos não é fruto do mero acaso, mas, conforme discutido por Correa (1995) e Correa et al. (1998), conseqüência da generalização de duas importantes experiências das crianças com quantidades: repartir quantidades e a vivência da relação de covariação direta em situações de vida diária.

No erro de Tipo I, as crianças mais velhas, em sua maioria, justificam sua resposta apontando para o fato de que a divisão não seria justa se os participantes não ganhassem quotas equivalentes (Justificativa II) ou então para a igualdade entre as quantidades a serem divididas pelos dois grupos (Justificativa III). Neste último caso, uma vez que as quantidades a serem repartidas são equivalentes, assegura-se, como conseqüência, a equivalência das quotas a serem distribuídas. A criança falha porque deixa de considerar que o número de bonecos em ambos os grupos é diferente. 
Tabela 5.

Distribuição das justificativas por idade segundo o tipo de erro (em \%).

\begin{tabular}{clrrrr}
\hline \multirow{2}{*}{ Idade } & & \multicolumn{5}{c}{ Justificativas } \\
\cline { 3 - 6 } & Erro & I & II & III & V \\
\hline \multirow{2}{*}{5} & Tipo I & 13.75 & 57.50 & 28.75 & .00 \\
& Tipo II & 10.42 & 59.38 & .00 & 30.20 \\
\multirow{2}{*}{6} & Tipo I & 7.69 & 51.28 & 41.03 & .00 \\
& Tipo II & 3.33 & 19.33 & .00 & 77.34 \\
\multirow{2}{*}{7} & Tipo I & .00 & 100.00 & .00 & .00 \\
& Tipo II & .75 & 5.22 & .00 & 94.03 \\
\hline
\end{tabular}

No erro de Tipo II, a criança vê que, apesar da igualdade entre as quantidades a serem divididas, o número de bonecos nos dois grupos é diferente, e que, portanto, a extensão da quota deverá variar em função do número de divisores. A criança interpreta a tarefa tendo como base a sua experiência diária em situações nas quais a covariação entre os fatores se dá freqüentemente em sentido direto (por exemplo, quando a criança cresce, seus sapatos e roupas são maiores; ver, também a este respeito Resnick e Singer, 1993) e afirma, então, que ganha mais o boneco que pertencer ao grupo com mais componentes.

\section{Discussão}

Em comparação aos dados provenientes de estudos anteriores (Correa, 1995; Correa et al., 1998), em que 30\% das criança de 5 anos, $55 \%$ das de 6 anos e $85 \%$ das crianças de 7 anos tiveram performance considerada acima dos níveis de chance, os índices de acerto obtidos pelas crianças nesta investigação mostram que julgamento dos valores relativos das quantidades em situações de divisão partitiva, tal qual apresentadas em nossas tarefas, é mais difícil de ser efetuado com quantidades contínuas do que com quantidades discretas.

No entanto, os resultados da presente investigação somados às evidências empíricas obtidas nestes estudos permitem o delineamento de um quadro teórico acerca do desenvolvimento inicial da habili- 
dade da criança em estabelecer comparações e fazer julgamentos relativos acerca do processo de divisão quando as tarefas não envolvem qualquer tipo de cálculo numérico.

Há que se assinalar, de início, que importantes mudanças acontecem entre os 5 e 7 anos de idade no que se refere à habilidade da criança em raciocinar sobre as relações elementares entre as quantidades no processo de divisão em termos relativos, tanto no que concerne ao índice de acerto nas tarefas bem como em relação ao tipo de justificativa dada pela criança após cada resposta. Neste sentido, observase um aumento, de acordo com a idade, da porcentagem de justificativas que fazem menção a fatores que são matematicamente relevantes à solução do problema, decrescendo, por sua vez, a freqüência de respostas sem justificativas ou daquelas acompanhadas por uma justificativa arbitrária. A maior parte das crianças que conseguem efetivamente resolver as tarefas fornece também explicação verbal apropriada para a sua solução.

A exemplo dos estudos anteriores com quantidades discretas (Correa, 1995; Correa et al., 1998), as tarefas que envolvem o julgamento de partilhas idênticas entre os grupos foram resolvidas mais facilmente do que as tarefas nas quais comparações entre os grupos envolviam uma relação de ordem inversa entre divisor e quociente.

Tais resultados, tomados num plano de conjunto, parecem indicar que a experiência da criança em estabelecer comparações entre partilhas idênticas não só precede, como também parece constituir experiência fundamental à criança para a compreensão das relações entre os termos envolvidos na operação de divisão.

Em termos do desenvolvimento cognitivo, poder-se-ia tentar estabelecer uma conexão entre a experiência da criança em repartir e o uso do esquema de correspondência como ferramentas básicas e iniciais para o estabelecimento de comparações e inferências acerca de quantidades envolvidas em situações de divisão.

A literatura reporta que crianças desde os cinco anos têm um entendimento explícito do princípio da correspondência e da equivalência entre quantidades (Frydman \& Bryant, 1988; Cowan \& Biddle, 1989), podendo, por exemplo, julgar a igualdade ou desigualdade en- 
tre dois conjuntos, mesmo sem usar consistentemente a contagem como estratégia para estabelecer a numerosidade de dois conjuntos.

No entanto, as exigências impostas pelas situações de repartir e dividir não são idênticas em termos cognitivos. As situações de repartir que a criança encontra em sua vida diária podem ser resolvidas a partir de procedimentos aditivos em que a criança, através do uso da correspondência termo a termo, pode, então, estabelecer a equivalência entre as quotas a serem dadas a cada participante, adicionando ou retirando quantidades. No entanto, a divisão, como uma operação multiplicativa, vai requerer o entendimento por parte das crianças das relações entre dividendo e divisor na determinação do valor do quociente. No caso da divisão partitiva, o tamanho de cada quota dependerá da razão entre o quanto há para ser dividido e o número de quotas a serem dadas.

As tarefas da Condição Mesma, em que tanto o tamanho do dividendo quanto o número de divisores são idênticos em ambos os grupos, permitem à criança o reconhecimento e interpretação da situação a partir dos esquemas de correspondência utilizados anteriormente e comumente em situações aditivas.

A resolução efetiva das tarefas da Condição Diferente, no entanto, impõe obstáculo relativo à própria natureza da operação multiplicativa, que se refere à instância da covariação. Nestas tarefas, uma vez que o número de divisores é diferente em ambos os grupos, é necessário que a criança estabeleça inferências acerca de como o tamanho da quota variará em relação a este fato. O progressivo aumento do índice de erros do Tipo II nas idades de 6 e 7 anos, mostra que a criança, pela habilidade que têm no uso dos esquemas de correspondência, sabe que o tamanho das quotas não podem ser idênticos em ambos os grupos. Resta, portanto, à criança estabelecer o sentido desta covariação. As relações diretas são aquelas mais experimentadas pelas crianças durante o seu desenvolvimento e, portanto, tomadas mais facilmente como paradigmas para a solução das tarefas.

É necessário que mais investigações sejam realizadas para que as hipóteses aqui delineadas em relação ao desenvolvimento inicial do conceito de divisão na criança possam ser, então, melhor elaboradas. 
No entanto, estes resultados, somados aos de outros estudos, indicam a importância dos esquemas de correspondência (Cowan \& Biddle, 1989; Frydman \& Bryant, 1988) e do uso de estimativas baseadas no julgamento dos valores relativos de quantidades (Correa et al., 1998; Correa, Spinillo et al., 1998; Singer, Kohn \& Resnick, 1997; Spinillo \& Bryant, 1991; Streefland,1982) como ferramentas cognitivas poderosas na construção das representações iniciais de conceitos lógicomatemáticos e, em particular, do conceito de divisão.

\section{Agradecimentos}

Nossos agradecimentos à FAPERJ e ao CNPq pelo apoio concedido. Às crianças que participaram deste estudo, aos seus professores e a sua escola pelo seu interesse e colaboração.

\section{Referências}

Brown, M. (1981). Number operations. In K. M. Hart (Org.), Children's understanding of mathematics (pp. 11-16). London: John Murray.

Bryant, P. E. (1974). Perception and understanding in young children. London: Methuen.

Correa, J. (1995). Young Children's Understanding of the Division Concept. Tese de doutorado não-publicada, University of Oxford, Oxford.

Correa, J., \& Bryant, P. (1994). Young children's understanding of the division concept. Proceedings of the XIIIth Biennial Meetings of ISSBD (International Society for the Study of Behavioural Development), 253.

Correa, J., Nunes, T., \& Bryant, P. (1998). Young children's understanding of division: the relationship between division terms in a non-computational task. Journal of Educational Psychology, 2, 321-329.

Correa, J., Spinillo, A. G., Brito, M. R. F., \& Moro, M. L. F. (1998). $O$ desenvolvimento de conceitos matemáticos: temas de interesse para a educação matemática. In M. L. S. de Moura, J. Correa \& A. G. Spinillo (Orgs.), Pesquisas Brasileiras em Psicologia do Desenvolvimento (pp. 73-110). Rio de Janeiro: EDUERJ.

Cowan, R., \& Biddle, S. (1989). Children's understanding of one-to-one correspondence in the context of sharing. Educational Psychology, 9, 133-140.

Desforges, A., \& Desforges, C. (1980). Number-based strategies of sharing in young children. Educational Studies, 2, 97-109.

Fischbein, E., Deri, M., Nello, M., \& Marino, M. (1985). The role of implicit models in solving verbal problems in multiplication and division. Journal for Research in Mathematics Education, 16, 3-17. 
Frydman, O., \& Bryant, P. E. (1988). Sharing and the understanding of number equivalence by young children. Cognitive Development, 3, 323-339.

Greer, B. (1992). Multiplication and division as models of situations. In D. A. Grouws (Org.), Handbook of research on mathematics teaching and learning (pp.276-95). New York: MacMillan.

Miller, K. (1984). Child as the measurer of all things: measurement procedures and the development of quantitative concepts. In C. Sophian (Org.), Origins of cognitive skills (pp. 193-228). Hillsdale: Lawrence Erlbaum.

Resnick, L. B., \& Singer, J. A. (1993). Protoquantitative origins of ratio reasoning. In T. P. Carpenter, E. Fennema \& T. A. Romberg (Orgs), Rational number: an integration of research (pp. 107-30). Hillsdale: Lawrence Erlbaum.

Singer, J. A., Kohn, S. A., \& Resnick, L. B. (1997). Knowing about proportions in different contexts. In T. Nunes \& P. Bryant (Orgs.), Learning and teaching mathematics: an international perspective (pp. 115-132). Hove: Psychology Press.

Spinillo, A.G., \& Bryant, P. (1991). Children's proportional judgements: the importance of 'half'. Child Development, 62, 427-440.

Streefland, L. (1982). The role of rough estimation in learning ratio and proportion: an exploratory research. Proceedings of the $6^{\text {th }}$ International Conference for the Psychology of Mathematics Education (PME), 193-199.

Jane Correa, doutora em Psicologia pela Universidade de Oxford, Reino Unido, é professora adjunta do Instituto de Psicologia da Universidade Federal do Rio de Janeiro. Endereço para correspondência: Rua Teixeira de Melo 47/804, Ipanema, 22410010, Rio de Janeiro, RJ.

Elisabet de Sousa Meireles e Cristina Soraia de Souza Curvelo são psicólogas formadas pela Universidade Federal do Rio de Janeiro. 